CrossMark

$<$ click for updates

\section{Y. Martinet ${ }^{1}$ \\ K. Fagerström ${ }^{2}$ \\ A. McNeill 3 \\ F. Godfrey ${ }^{4}$}

${ }^{1}$ Service de Pneumologie, $\mathrm{CHU}$, Nancy, France.

${ }^{2}$ Smokers Information Centre, Helsingborg, Sweden.

${ }^{3}$ Dept of Epidemiology \&

Public Health, University

College London, London, UK.

${ }^{4}$ EU Policy Adviser, ERS Office, Brussels, Belgium.

\title{
Harm reduction strategies for tobacco smoking: report from an ERS Research Seminar
}

Against the background of the profound and

well-known health risks associated with tobacco smoking, the European Respiratory Society (ERS) organised a Research Seminar in Ferney-Voltaire (France) on October 3-4, 2005, in order to explore the feasibility of harm reduction (HR) approaches.

At the meeting, a number of presentations were given, ranging from the basic mechanisms of nicotine dependence, the toxicity of smoked and non-smoked tobacco and pure nicotine-containing products, to the policy aspects of various HR approaches.

The participants comprised civil servants from health branches of some governments, ERS officials and ERS members with a special interest in the field.

\section{The main messages from the Seminar}

Nicotine exhibits all the principal properties of a drug of dependence, but appears to contribute little to overall disease caused by tobacco use. Improved health outcomes were observed when non-combustible nicotine delivery devices were used compared with smoking.

Conditionary reinforcers and pharmacologically active substances in tobacco other than nicotine may play a role in the addiction to tobacco smoking. In Sweden, for example, where more males now use snuff rather than smoke, it has been suggested that it may be easier for smokers to transfer their dependence to another form of tobacco than to pure nicotine.

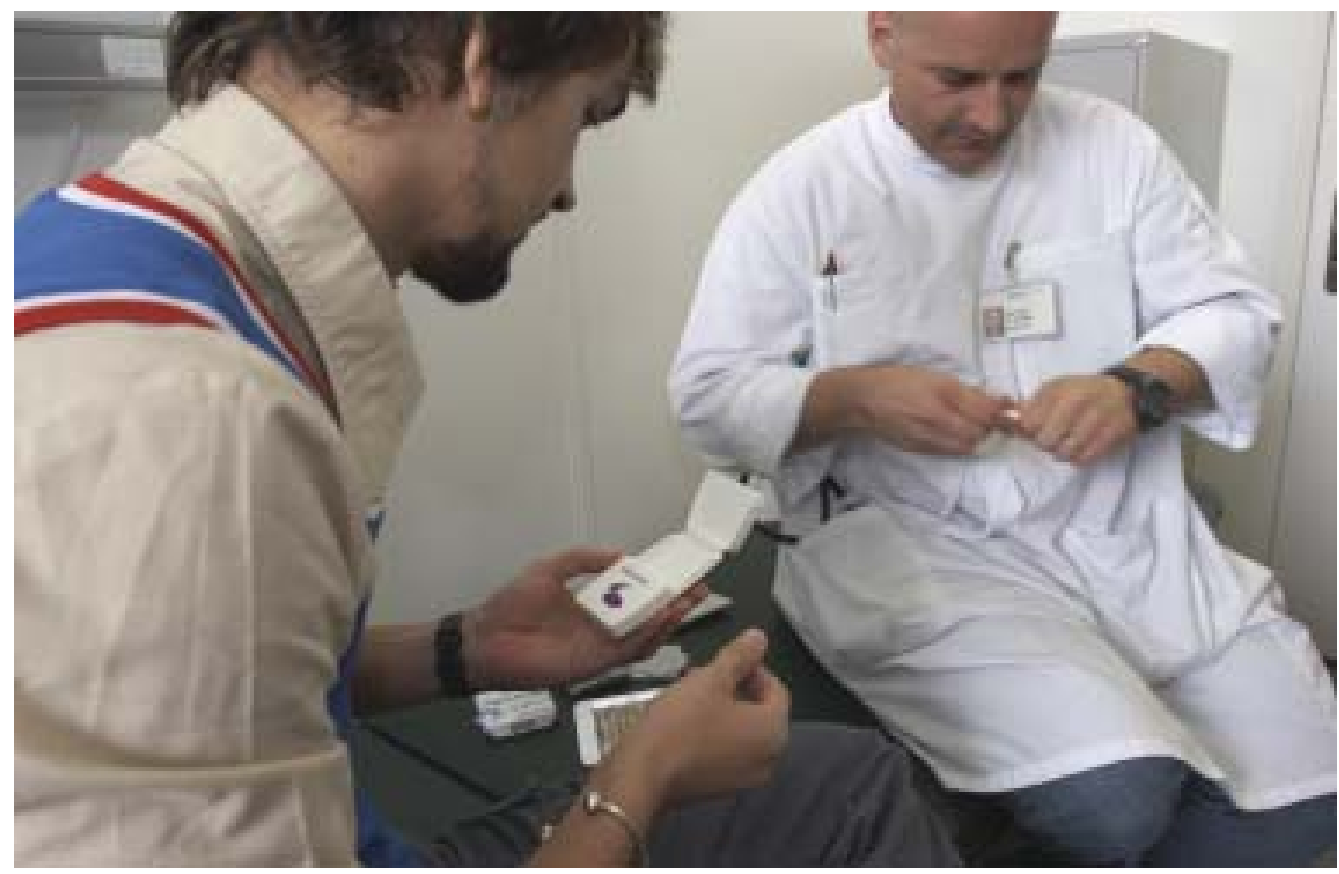


Tobacco control is not recognised as a medical and academic discipline, and it may therefore be important for tobacco HR to learn from other drug addictions, in particular patterns of heroin use and the introduction of needle-sharing programmes and methadone substitution.

Although agreeing on the basic premises that certain products are much less toxic than others, there was ambivalence in moving forward because of the possible role of the tobacco industry as a purveyor of the products. In general, the industry has a blemished record and some delegates would be reluctant to help it survive in a new marketplace even with less harmful products. However, to a large degree, this can be taken care of by a European Union (EU) or local Regulatory Agency that should regulate all nicotine-containing products. Thus, it was felt that an appropriate regulatory framework and regulatory authority were urgently needed.

With the current mix of tobacco-control strategies and assuming continued declines in smoking prevalence, it will take several decades to eliminate smoking completely, and much longer in certain populations and countries. Some participants felt that alternative less harmful products would be necessary in order to achieve a near-zero smoking prevalence. By doing nothing, the status quo would remain, cigarettes will dominate and the tobacco-control movement will be out of line with the science.

In addition, the Seminar participants discussed the priorities for tobacco-product regulation, i.e. whether this should be regulating conventional cigarettes, potentially reduced exposure products, smokeless tobacco or nicotine replacement therapy. It was also questioned whether a goal should be set for removing combustible tobacco products from the market. Political interest in reduced ignition propensity cigarettes is growing in Europe, as well as in reducing the yields of certain toxins from cigarette smoke. However, without a firm goal to end smoking, reduced toxicity cigarettes could be seen as cementing the continuance of smoking, instead of as a precautionary protective measure for smokers until such time as cigarettes are no longer sold. Also, it was recognised that little is known about how interested smokers are in $\mathrm{HR}$ and which types of products they would consider using.

In conclusion, it was proposed that an ERS Task Force should be set up to focus specifically on HR in Europe.

Material from the presentations given at the Harm Reduction Strategies Seminar is available at www.ersnet.org/elearning

\section{The main recommendations}

Following discussions, a draft consensus statement of the meeting was revised as follows.

- $\quad$ HR is desirable as part of a comprehensive tobacco-control programme.

- Nicotine is not the main cause of health problems.

- Combustible products cause the most harm.

- The status quo should not continue.

- Snuff is a lot less harmful than cigarettes.

- Snuff also has potential as a smokingcessation aid.

- Lifting the EU ban on snuff within a proper regulatory framework needs to be considered.

- The playing field for "clean nicotine" should be levelled via deregulation and taxation and pricing measures.

- Toxic ingredients should be removed from conventional cigarettes.
ERS Research Seminars gather together a limited number of well-established investigators with a view to address scientific topics in depth and break new ground, through examining newly published work and research in progress. The Seminars last for 2 days and are located in easily accessible European cities. For more information, visit www.ersnet.org 